\title{
Production of Topology-optimised Structural Nodes Using Arc-based, Additive Manufacturing with GMAW Welding Process
}

\author{
Jan Reimann, Philipp Henckell, Yarop Ali, Stefan Hammer, Alexander Rauch, Jörg \\ Hildebrand, Jean Pierre Bergmann \\ Technische Universität Ilmenau, Ilmenau D-98684, Germany \\ E-mail: jan.reimann@tu-ilmenau.de
}

Received: 30 January 2021; Accepted: 29 March 2021; Available online: 30 April 2021

\begin{abstract}
The desire to generate a stress optimised structural node with maximum stability is often coupled with the goal of low manufacturing costs and an adapted and minimal use of material. The complex, three-dimensional free-form structures, which are created by means of topology-optimisation, are only partially suitable for conventional manufacturing. The wire arc additive manufacturing (WAAM), by means of arc welding processes, offer a cost-effective and flexible possibility for the individual production of complex, metallic components. Gas metal arc welding (GMAW) is particularly suitable to produce large-volume, load-bearing structures due to buildup rates of up to $5 \mathrm{~kg} / \mathrm{h}$. The generation of strength and stiffness adapted support structures by means of the numerical simulation method of topology-optimisation was investigated in this study to generate topologyoptimised structural nodes. The resulting node is transferred into a robot path using CAD/CAM software and manufactured from the filler material G4Si1 using WAAM with the GMAW process. Based on the boundary conditions of the WAAM process, the path planning and thus the manufacturability of the topology-optimised supporting structure nodes is evaluated and verified using a sample structure made of the welding filler material G4Si1. Depending on the path planning, an improvement of the mechanical properties could be achieved, due to changes in $t_{8 / 5}$ times.
\end{abstract}

Keywords: WAAM; Wire arc; GMAW; Gas metal arc welding; Wire-based; Arc; Additive manufacturing; Topology-optimisation.

\section{Introduction}

Stress-optimised structures, which have been designed based on nature (bionics), are becoming increasingly important. Strength and stiffness-adapted supporting structures as well as iconic architecture and individual aesthetics can be realised. The motivation of a lightweight node structure with maximum stability is often coupled with the desire for minimal and adapted material use and low manufacturing costs.

Over the last decades, topology-optimisation has established itself in various engineering disciplines as a robust tool for optimising material distribution within a given design space [1-5]. Topology-optimisation typically results in complex and abstract structures with undercuts and cavities. These structures cannot be produced with conventional manufacturing methods, or only to a limited extent. Therefore, a manufacturing technology for loadbearing structures made of metals is required with which these topology-optimised structures can be produced. Additive manufacturing (AM) processes offer the necessary freedom of design to produce highly complex components. This paper presents a production and process strategy view regarding a topology-optimised structural node, which was previously published in [6].

Additive manufacturing describes the layered construction of three-dimensional objects by the targeted application or joining of wire, powder or foil materials made of metal or plastic [7]. Which allows to produce complex geometries from a batch size of 1 with a resource-efficient material application.

$\mathrm{Up}$ to now, the production of complex metallic 3D components has mainly been realised by laser-based processes. The processes used for this purpose are Direct Energy Deposition (DED) and powder bed fusion by laser (PBF). The powder bed process in particular is severely limited in productivity for larger components due to the achievable layer thicknesses of a few tenths of a millimetre and a low build-up rate of approx. $1-10 \mathrm{~cm}^{3} / \mathrm{h}$. This results in long production times and limited component dimensions [8-10]. The laser-based DED process offers build-up rates of approx. $300 \mathrm{~cm} / \mathrm{h}-700 \mathrm{~cm}^{3} / \mathrm{h}$ and layer thicknesses of up to $1.5 \mathrm{~mm}$, which results in a significantly higher productivity than PBF processes [11].

Galjaard et. al. carried out the topology-optimisation of a structural node for a tensegrity structure, which is only stressed in tension. After the optimisation, the node was produced additively in a Laser PBF process. For 
reasons of production time and costs, the component was manufactured in $40 \%$ of its original size. The authors estimate that the production in original size would have taken about 15 days with today's means, which in combination with the high powder costs renders the component uneconomical to produce [12].

Wire arc additive manufacturing (WAAM) can achieve significantly higher build-up rates, which has made it the focus of attention in recent years [13]. Figure 1 shows an example of the WAAM process chain, taking topology-optimisation into account. WAAM can utilise gas metal arc welding (GMAW), the tungsten inert gas welding (TIG), as well as plasma processes during additive manufacturing. In these processes, a layer-by-layer structure is realised by feeding and melting a wire-shaped filler material. This process enables the generation of undercuts, cavities for lightweight construction applications or any cooling channels running in the component which cannot be produced or can only be produced to a limited extent using conventional methods (e.g. [14, 15]). The GMAW process is particularly characterised by its cost-effective and robust process technology for additive manufacturing. Due to the local inert gas cover, there are no restrictions for the workspace size. In addition, the coaxial supply of filler material makes it possible to work independent of direction. Depending on the material and component geometry, the WAAM process using GMAW welding technology allows deposition rates of approx. 5 $\mathrm{kg} / \mathrm{h}[16,17]$.
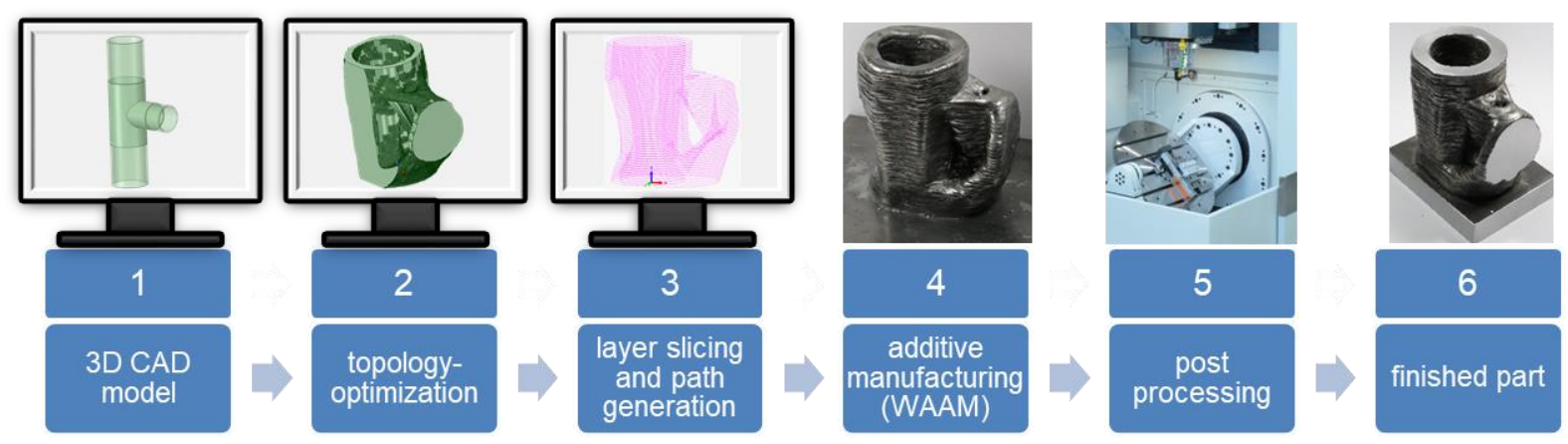

Figure 1. Process chain of additive manufacturing using WAAM according to [12].

\section{Experimental methods of additive manufacturing}

The welding tests and additive manufacturing of the topology-optimised structural nodes were carried out using an GMAW welding power source "EWM alpha Q 552 Expert 2.0 puls MM". The welding tests were carried out with the energy-reduced short arc technology "coldArc". A 6-axis industrial articulated arm robot "Kuka KR1502 " was used to ensure reproducible torch movement.

As base material (substrate) $\mathrm{S} 355 \mathrm{~J} 2+\mathrm{N}$ with a thickness of $20 \mathrm{~mm}$ was used. The additive structure (Figure 2) was realised with the low-alloyed solid wire electrode DIN EN ISO 14341-A-G4Si1. To determine suitable welding parameters, preliminary tests were carried out on wall structures, which were $300 \mathrm{~mm}$ long and $160 \mathrm{~mm}$ in hight, with different energy inputs, with widths of one, two or three weld beads (Figure 2 right) and varying overlaps. In addition, a parameter set with a meandering path planning was tested Tensile samples were taken from additive manufactured wall structures along and across the build-up direction. In addition, the $t_{8 / 5}$ time was measured using a thermocouple type $\mathrm{C}$. The approach of using parallel weld beads to increase the structure width comes from the field of filling strategies for volume bodies. Usually, a meander path or an increase in the material discharge is used to widen the weld bead. For surface filling in solids, meander paths are sometimes used, but also contour-parallel and line filling. In analogy to this, a meandering path, parallel welding beads and an increase in material output are now to be used to create wide wall structures. The knowledge gained can in turn be transferred to more complex bodies. The underlying idea for using the welding beads is to reduce the heat input at each point in time in order to reduce the heat build-up.

Un- and low alloyed steel is commonly characterized during welding by its $t_{8 / 5}$ time according to DIN EN 10112:2001-05 [18]. It describes the cooling time of the weld bead and the heat effected zone (HAZ) in a temperature interval between $800^{\circ} \mathrm{C}$ and $500^{\circ} \mathrm{C}$. This temperature range is decisive for the mechanical properties due to the phase transformation from $\gamma$ - to $\alpha$-phase.

The CAD/CAM program DCAM 2018 from SKM was used to slice the 3D component, i.e., to break it down into layers, which makes sequential 2D contour generation possible. The path planning was created from this. Finally, an integrated post-processor is used to convert the data into the Kuka programming language. 


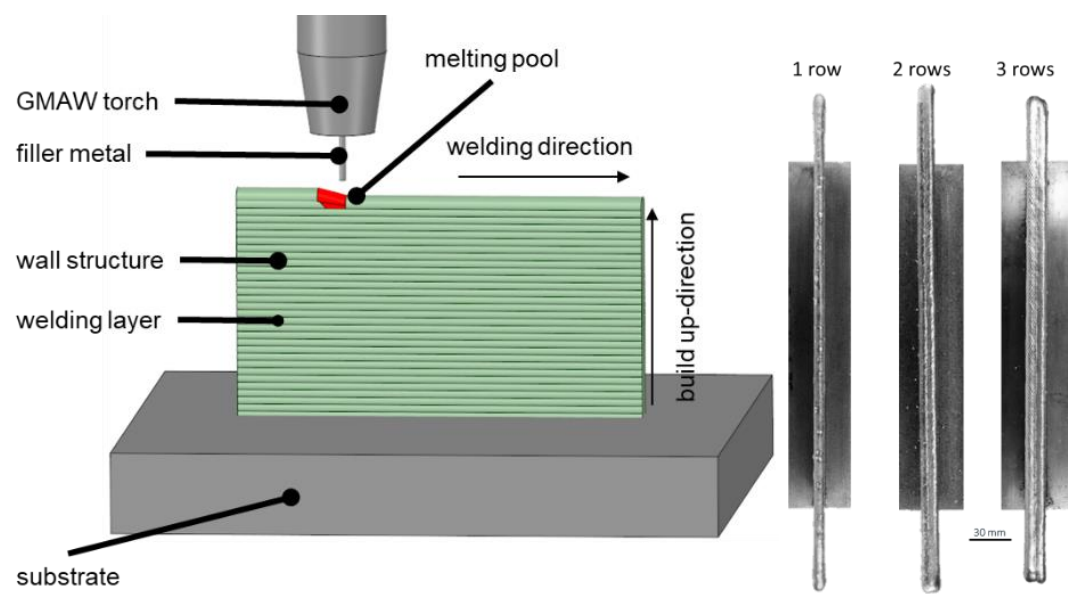

Figure 2. additive manufacturing of a wall structure (left: schematic of WAAM process; right: wall structures with one, two and three adjacent rows)

\section{Results and discussion}

In preliminary parameter studies three parameter sets found to be suitable for additive manufacturing of G4Si1 in general and were investigated further to ensure the mechanical properties of thick structures are suitable to generate loadbearing parts. Thereby $t_{8 / 5}$ time and energy input were related to each other.

Different wall thicknesses were tested throughout the course of this investigation with varying energy inputs per unit length at $4 \mathrm{~kJ} / \mathrm{cm}, 6 \mathrm{~kJ} / \mathrm{cm}$ and $8 \mathrm{~kJ} / \mathrm{cm}$. The thickness was varied between $6 \mathrm{~mm}$ for one row, to up to 12 $\mathrm{mm}$ for three rows and the meandering wall structure.

The mechanical properties of the weld metal are primarily determined by its chemical composition and the rate at which it cools from the liquid phase. Welding temperature cycles are generally characterised by the time required to pass through a certain temperature interval. The cooling time from $800^{\circ} \mathrm{C}$ to $500^{\circ} \mathrm{C}\left(\mathrm{t}_{8 / 5}\right.$ time $)$ has proven itself in welding technology to characterise the mechanical-technological properties of the weld metal [19].

The $t_{8 / 5}$ times were measured in the middle of the wall structure at the $150 \mathrm{~mm}$ length mark and at a height of $80 \mathrm{~mm}$ (40th layer). This position was chosen because a quasi-static condition for the cooling time occurs after 20 deposited layers according to Henckell et. al. [20], and the chosen position is well above this boundary condition. The aim was to achieve the highest possible significance of the values. Due to the periodic heating, there are several $t_{8 / 5}$ times for each welding layer. In these tests, the last $t_{8 / 5}$ cycle was used for evaluation, as this is the last complete cycle of the $\gamma$ - to $\alpha$ - transformation.

It can be seen from the plots that the $t_{8 / 5}$ times for G4Si1 (Figure 3) increase with increasing energy input per unit length. Furthermore, the $t_{8 / 5}$ times decrease with increasing number of rows. In order to be able to evaluate additive manufacturing using the GMAW process for samples generated in multiple rows, the cooling time ( $t_{8 / 5}$ time) is considered for the different numbers of rows. Figure 3 shows that the $t_{8 / 5}$ time decreases with increasing number of rows and is halved in the comparison of single-row generated samples to three-row generated samples at a line energy of $4 \mathrm{~kJ} / \mathrm{cm}$. The reduction in $\mathrm{t}_{8 / 5}$ time is evident for both materials and all line energies used.

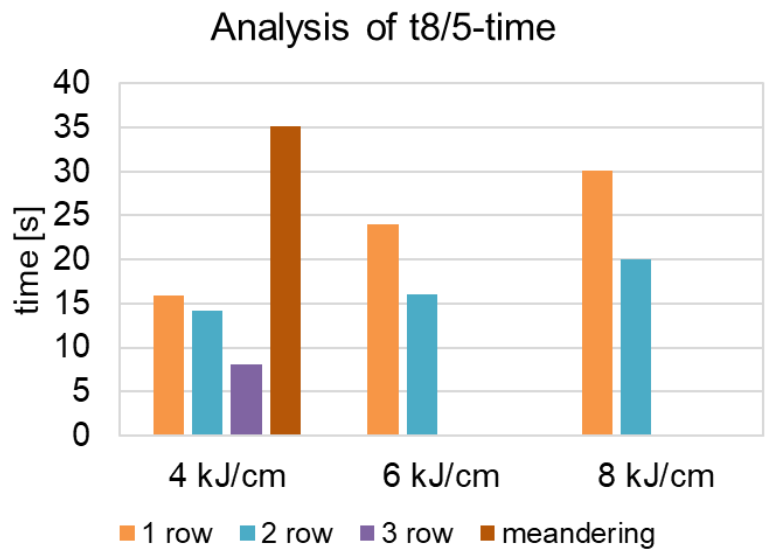

Figure 3. left: $t_{8 / 5}$ time compared to energy input and number of rows 
The fastest cooling time ( $\mathrm{t}_{8 / 5}$ time) was measured at $4 \mathrm{~kJ} / \mathrm{cm}$ line energy and three-row build-up with $8 \mathrm{~s}$. The slowest cooling time ( $\mathrm{t}_{8 / 5}$ time) was recorded with $4 \mathrm{~kJ} / \mathrm{cm}$ line energy and meandering generation of the wall structure.

To evaluate the tensile tests, the first step was to examine the mechanical properties of the specimens generated in welding direction and in build-up direction from the point of view of possible dependencies.

The following Figure 4 shows the tensile strength and the yield strength for G4Si1 as a function of the specimen orientation with a number of specimens of $n=3$. Only very small deviations of the tensile strength and yield strength for different specimen orientations are shown there. The examination of the respective test results for the tensile strength do not reveal any significant deviations with regard to the specimens generated in welding direction and in build-up direction. In this respect, the present test results do not allow any conclusions to be drawn about different mechanical properties in the different directions considered for this material.

Figure 4 illustrates the resulting tensile and yield strength with their corresponding energies. The tensile strength in build-up direction and in welding direction are within margin of error of each other, which leads to the conclusion that the mechanical properties are nearly homogeneous on moth directions. It is evident that the mechanical strength increases with decreasing energy input and increasing number of rows (Figure 4). Moreover, the meandering welding path achieved the lowest overall strength of all tested parameter sets. To achieve at least a yield strength as high as the value in the datasheet of G4Sil (460MPa), it is necessary to use a low energy parameter set and use a building strategy with at least two rows of thickness.
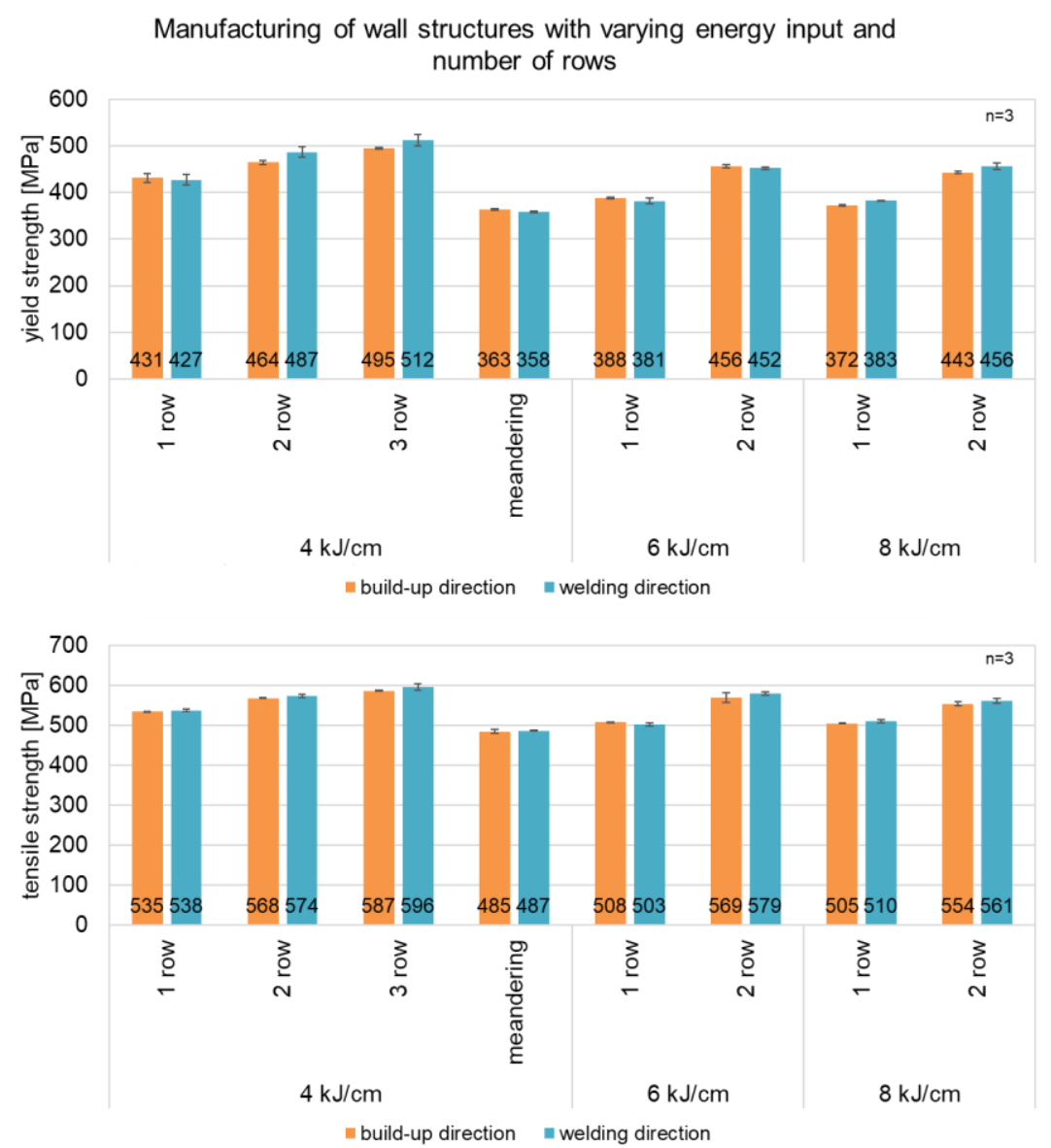

Figure 4. tensile and yield strength in build-up and welding direction compared to energy input and path planning strategy

Furthermore, a lower line energy and a higher number of rows lead to better mechanical properties, i.e., higher strength. This is due to the lower $\mathrm{t}_{8 / 5}$ times for lower line energies and a higher number of rows. This can be clearly seen in Figure 5 using a wall thickness of $9 \mathrm{~mm}$ and $12 \mathrm{~mm}$ as a reference for G4Si1. The results show that the use of a parallel with two rows build up approach for a thickness of $9 \mathrm{~mm}$ will increase the tensile strength by more than $12 \%$ and the yield strength by nearly $25 \%$ in comparison to a generation via one weld bead. The results for a structure width of $12 \mathrm{~mm}$ are comparable to the smaller structure width. Therefore, a parallel build up of three welding beads with lower energy input is more suitable to achieve better mechanical properties than the 
datasheet states. The tensile strength for a build up with three parallel rows could be increased by nearly $6 \%$ compared to two parallel rows and nearly by $22 \%$ with meandering. Moreover, the yield strength for three rows is $12 \%$ higher than for two rows and nearly $40 \%$ higher than a meandering path planning.

A structural design shows better mechanical-technological properties for the same wall thicknesses when a low line energy is used in a multi-row design.
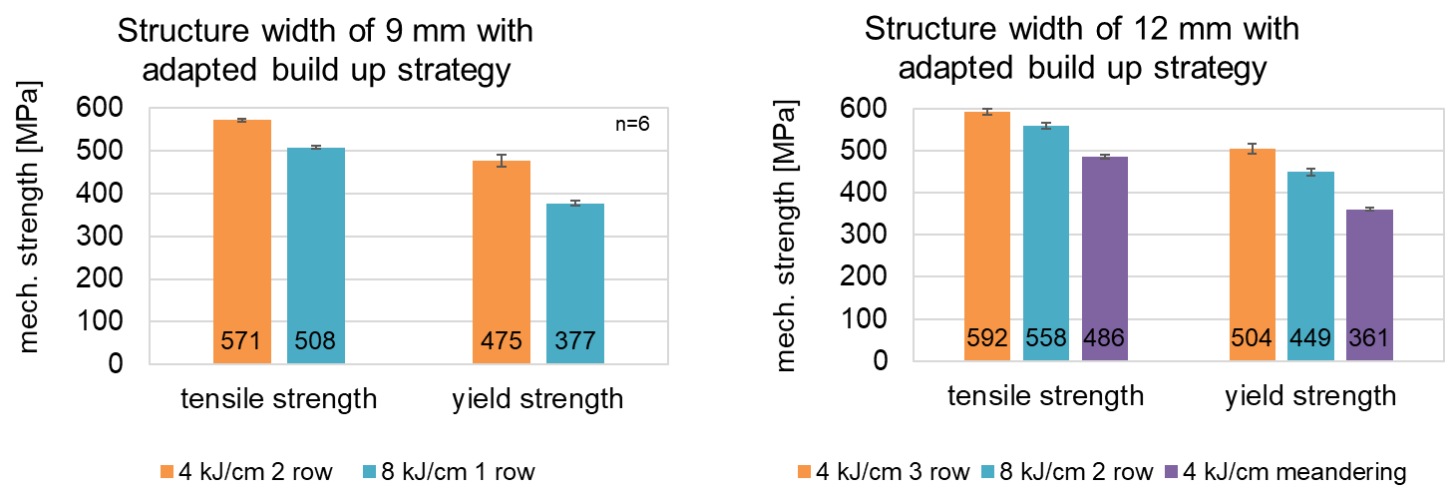

Figure 5. Comparison of mechanical strength for varying energy inputs and path planning strategies for two different withs

\section{Production of topology-optimised node geometry}

After finishing the evaluation of the mechanical properties of G4Si1 in additive manufacturing it could be ensured, that the minimal needed yield strength of approx. $420 \mathrm{MPa}$ to generate a structural node as calculated by Reimann et. al. could be achieved [6]. The production of a complex structure using WAAM often requires reworking in $\mathrm{CAD}$, as it is only possible to a limited extent to produce horizontal overhangs or structures with a deviation of more than $40^{\circ}$ from the vertical in a layer-by-layer, 3-axis design. The reason for this is that, unlike other additive manufacturing processes, the WAAM process does not use supporting structures. Therefore, the geometry was reworked in the ANSYS SpaceClaim Design Modeler to ensure manufacturability. Figure 6 shows the original geometry. The red marked areas had to be adjusted to ensure manufacturability. The horizontal overhangs of the structure were removed, and the overhang angle of the connection area was slightly adjusted to achieve an angle of $40^{\circ}$ to the vertical.
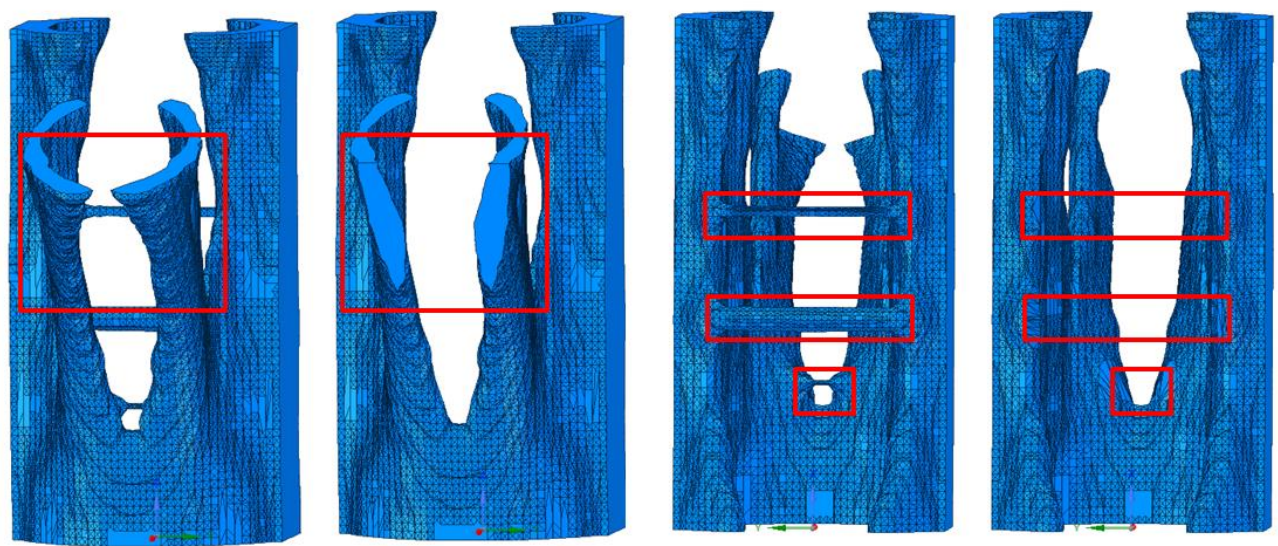

Figure 6. Improving the manufacturability of the $30^{\circ}$ oblique joint.

As stated, before it was possible to achieve the needed mechanical properties to be able to manufacture a structural node with the needed properties. Considering the approached $420 \mathrm{MPa}$ three different parameter sets could be used (Figure 5). The parameter with $4 \mathrm{~kJ} / \mathrm{cm}$ and at least 3 adjacent rows was used for the production of the structural node in order to have a sufficient reserve between the resulting mechanical properties and the needed properties to ensure sthe stability and longevity of the structural node. Using this parameter set 208 layers of 1.8 $\mathrm{mm}$ each were needed to achieve a resulting overall height of approx. $375 \mathrm{~mm}$. Figure 7 shows the path planning for the component and the top welding layer. It can be seen that the top layer has three welding paths with contourparallel filling strategy, which results in six adjacent welding beads. The component was produced with a contour- 
parallel filling strategy to improve the connection between the welding beads inside the component. This should result in slightly better mechanical properties than presented in the tensile tests, because of a higher wall thickness, which might add up to an even better safety factor.

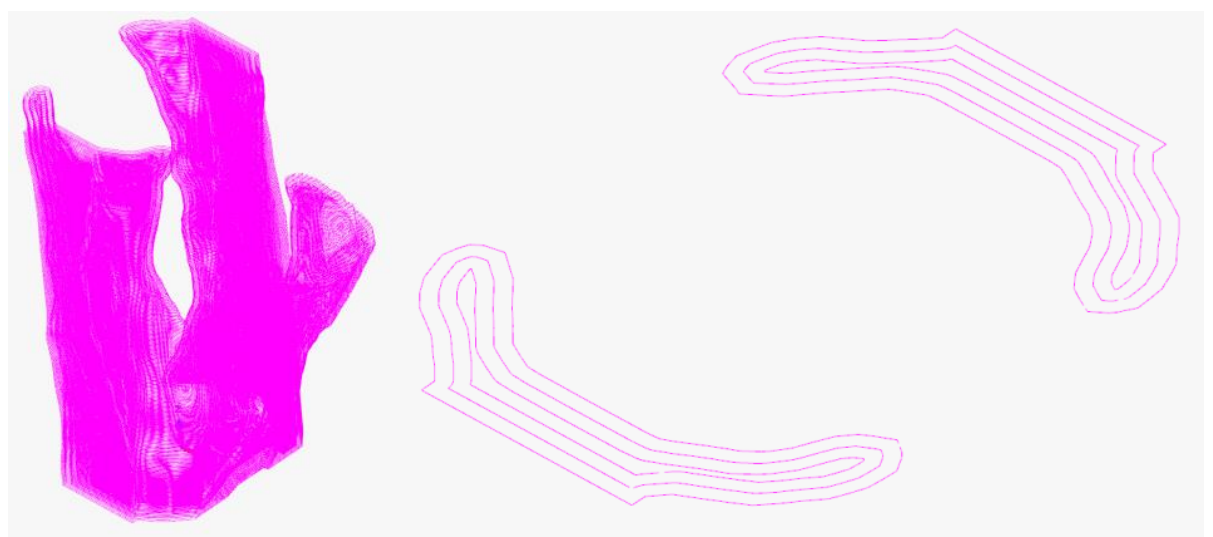

Figure 7. Path planning (left: entire component; right: top welding layer)

The component was produced on a substrate plate using the GMAW welding process. The assembly was carried out in a layer by layer process and an interpass temperature of $100^{\circ} \mathrm{C}$ was maintained. Figure 8 shows the additively manufactured, topology-optimised component which was cleaned and not yet removed from the substrate.

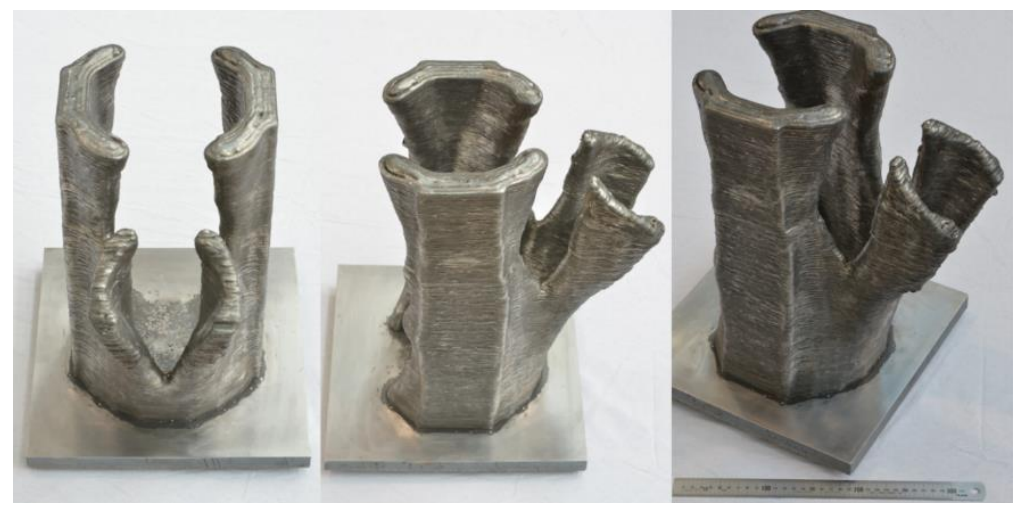

Figure 8. Additively manufactured, topology-optimized $30^{\circ}$ oblique joint.

\section{Conclusion and outlook}

This study has shown that the build-up strategy is as important as the overall welding parameter set to achieve the desired mechanical properties for additively manufactured structures. Therefore, a parameter set with low energy input and a build-up strategy with adjacent rows of welding beads rather than meandering should be used for the additive manufacturing, if possible, due to the increasing tensile and yield strength. The increase in mechanical strength can be traced back to a decreasing $t_{8 / 5}$ time for wider structures, due to a better capability to transfer heat away from the last welded layer.

Despite the high degree of design freedom in additive manufacturing, it became apparent during the production of the node that reworking of the design is absolutely necessary, since today's boundary conditions of topologyoptimisation do not offer the possibility of defining limiting angles in advance or avoiding horizontal overhangs. One way of counteracting this is to use a 5-axis machining strategy in which the welding torch can be moved in $\mathrm{x}$, $\mathrm{y}$ and $\mathrm{z}$ directions and the component can be positioned under the welding torch using a turn-tilt table. This allows to avoid constrained positions and to create arbitrary angular positions and even overhangs, as the welding torch itself is always in a neutral position.

The use of additive manufacturing makes it possible to create geometries which cannot be produced or can only be produced to a limited extent using conventional methods, which can result in a significant added value in production. However, when calculating and using additive manufacturing processes, it must be considered that reworking is necessary for components, especially for connecting and functional surfaces. 


\section{Acknowledgement}

This article is based on results obtained in a research project funded by "Zukunft Bau" research initiative of the Federal Institute for Research on Building, Urban Affairs and Spatial Development (BBSR) (AZ: SWD10.08.18.7-17.46). The author is responsible for the content of the publication. We would like to thank EWM® AG for providing the welding equipment and Westfälische Drahtindustrie $\mathrm{GmbH}$ for providing the filler material.

\section{References}

[1] Abdelwahab M, Tsavdaridis K. Optimised 3D-printed metallic node-connections for reticulated structures. In: The 9th International Conference on Steel and Aluminium Structures, 03-05 Jul 2019. Bradford, UK.

[2] Bikas H, Stavridis J, Stavropoulos P, Chyssolouris G. A design framework to replace conventional manufacturing processes with additive manufacturing for structural components: A formula student case study. In: Procedia CIRP (Volume 57). 2016. p.710-715.

[3] Hintereder J, Sattler S, Gunzert U. Development of a disruptive lightweight semitrailer truck. ATZ Automotive Magazine Special Issue 3. 2018. p.104-111. (in German)

[4] Suksuwan A, Spence S. Performance-based multi-hazard topology optimization of wind and seismically excited structural systems. Engineering Structures. 2018;172:573-588..

[5] Tsavdaridisa K, Efthymioub E, Aduguc A, Hughesd J, Grekavicius L. Application of structural topology optimisation in aluminium cross-sectional design. Thin-Walled Structures. 2019;139:372-388.

[6] Reimann J, Hammer S, Henckell P, Ali Y, Hildebrand J, Bergmann JP. Topology optimized structural nodes. Industrie 4.0 Management 4. 2020. p.15-19. (in German)

[7] VDI- Department of Production Engineering and Manufacturing Processes. Additive manufacturing processes, rapid manufacturing - Basics, definitions, processes. VDI-Gesellschaft Produktion und Logistik. 2014. (in German)

[8] Bundesverband der Deutschen Industrie. Implications of 3D printing for securing raw materials in German industry. Position Paper Security and Raw Materials. 2016. (in German)

[9] Berger R. Additive manufacturing - next generation Amnx. Roland Berger. 2016. (in German)

[10] Peters S. Additive manufacturing - the path to individual production. Hessen-Nanotech 25. 2015. (in German)

[11] Brockmann R, Candel-Ruiz A, Kaufmann S, Müllerschön O. Strategies for high deposition rate additive manufacturing by laser metal deposition. ICALEO 2015. p.680.

[12] Galjaard S, Hofman S, Ren S. New opportunities to optimize structural designs in metal by using additive manufacturing. Advances in Architectural Geometry. 2014. p.79-93.

[13] Bergmann JP, Henckell P, Ali Y, Hildebrand J, Reimann J. Basic scientific conceptualization of existing challenges and perspectives for additive manufacturing with electric arc. DVS-Berichte Band 345. 2018. (in German)

[14] Hildebrand J, Ali Y, Ullrich J, Dahms S, Eilenberger D, Bergmann JP, Seul T, Jahn S. Use of arc and diffusion welding technology for additive manufacturing of large temperature-controlled tools. Tagungsband Werkstoffe und Additive Fertigung. 2018. p.121-126. (in German)

[15] Jahn S, Gemse F, Broich U, Sändig S. Efficient diffusion bonding of large scale parts. Materials Science Forum (Vol. 838). 2015. p.838-839.

[16] Martina F. Recent developments in large-scale wire+arc additive manufacturing. Additive Manufacturing in Aerospace, ILA Berlin. 2016.

[17] Ding D, Pan Z, Cuiuri D, Li H. Wire-feed additive manufacturing of metal components: technologies, developments and future interests. International Journal of Advanced Manufacturing Technology. 2015;81:14.

[18] DIN EN 1011-2:2001-05. Welding-Recommendation for welding of metallic materials-Part 2: Arc welding of ferritic steels. Beuth Verlag. 2001.

[19] Stahlinstitut VDEh. Weldable non-alloy and low-alloy steels - recommendations for processing, especially for fusion welding. Beuth Verlag. 2017.

[20] Henckell P, Gierth M, Ali Y, Reimann J, Bergmann JP. Reduction of energy input in wire arc additive manufacturing (WAAM) with gas metal arc welding (GMAW). Materials. 2020;13(11):2491.

(C) 2021 by the author(s). This work is licensed under a Creative Commons Attribution 4.0 International License (http://creativecommons.org/licenses/by/4.0/). Authors retain copyright of their work, with first publication rights granted to Tech Reviews Ltd. 